\title{
COMPARATIVE ANALYSIS OF THE BUCKLING FACTOR OF THE STEEL ARCH BRIDGES
}

\author{
Sigutė ŽILE்NAITE் \\ Vilnius Gediminas Technical University, Sauletekio al. 11, LT-10223, Vilnius, Lithuania
}

Received 17 October 2018; accepted 01 February 2019

\begin{abstract}
The dominant axial compressive force makes the arches become extremely sensitive to the loss of stability. Their stability analysis was first initiated in the late 20th century. The first stability research of single arches was carried out inplane at the elastic stage of the arches. Later the behaviour of arches in the elastic-plastic stage, the initial stresses and geometric imperfections before the arch buckles were also assessed, the effective length of the arches and the out-of-theplane arch strength conditions were being identified as well as the effect of the temperature on the stability of the arch. The expression of the critical force of the arches connected by vertical hangers with a chord and its dependant elements were defined by Petersen in the late 20th century. The design methodology for the formal design of arches connected by vertical hangers with a stiffening girder is presented in Annex D of the Eurocode 1993-2. Nevertheless, the area of application and the main assumptions are not defined. The first part of the comparative analysis identifies the assumptions for arch bridge modelling under which the buckling factor $\beta$ dependence curves in Figure D.4 of Annex D to Eurocode 1993-2 can be applied. In the second part a comparison of the the normative $\beta E C$ factor value and the one established by the numerical experiment with the increase in the number of hangers and change in the hanger network form is presented.
\end{abstract}

Keywords: buckling length factor, comparative analysis, steel bridge, network arch.

\section{Introduction}

The arch bridges are some of the most popular, the oldest and the most elegant bridges built in the urban and suburban areas. However, the dominant axial compressive force makes the arches become extremely sensitive to the loss of stability in plane and out of the plane of the arches. The summarized overviews of the stability of single arches and arch bridges can be found in the published articles (Pi \& Trahair, 1999; Pi \& Bradford, 2006) as well as in books (Galambos, 1988; Ziemian, 2010). The first stability research of single arches was carried out in-plane at the elastic stage of the arches. Major contribution to the analysis of the stability of single arches was made by the following scientists: Pi, Trahair and Bradford. Pi and Trahair (1999) examined the in-plane stability of the single two-hinged circular steel arches in the elastic-plastic stage while Pi and Bradford (2004), Pi, Bradford, and Tin-Loi (2008) analysed the rigidly fixed arches. Gradually the horizons were broadened by the analysis of nonlinear structure behaviour of arches. The assessments of the geometric imperfections and the initial stresses of the arch behaviour prior to buckling (Pi \& Trahair, 1999; Pi \& Bradford, 2004;
Pi et al., 2008; Zhao, Guo, \& Dou, 2013) were initiated. Meanwhile, the latest trend is the effect of temperature on the stability of single steel arches (Backer, Outtier, De Pauw, \& Van Bogaert, 2010; Guo, Wang, Lu, Zhang, \& Zhu, 2016; Heidarpour, Bradford, \& Othman, 2011; Pi \& Bradford, 2014).

The expression of the critical force of the arch bridges with vertical hangers was known since the late 20th century (Lebet \& Hirt, 2013). It is the usual expression of Euler's critical force with an additional coefficient $\mathrm{C}$ the numerical value of which depends on the ratio between the height of the arch rise and the span length, the ratio between the arch and the stiffening girder, the number of hangers and their cross-sectional area. In formal terms in order to ensure the stability of single arches or arch bridges, Table D.4 (single arches) and Figure D.4 (arch bridges) of Annex D, of the Eurocode 1993-2 (Lietuvos standartizacijos departamentas, 2007) are applicable. In Figure D.4 the buckling length factor values $\beta$ EC are presented as curves, which depend on the number of hangers as well as on the height of the arch rise and the span length.

${ }^{*}$ Corresponding author. E-mail: zsigute@yahoo.com 
With the emergence of the new arch bridge form in the middle of the 20th century - the network arch bridge the classical expression of the critical force acquired a new shape (Graße, Teich, Tveit, \& Wendelin, 2004; Schanack, 2009; Tveit, 2005; Brunn, Schanack, \& Steimann, 2004). In the oldest version the buckling resistance of the single arch is viewed as the performance of the general system of the arch and the stiffening girder interconnected by elastic supports - the hangers (Teich, 2011; Tveit, 2005). So far it is the only expression of critical force, which also evaluates the bending stiffness of the stiffening girder. The second (populist) expression of the critical force is described as the sum of the Euler force of the flexibly fixed rod and the total support forces against elastic supports (Heidarpour et al., 2011). This expression is rich in geometric indices such as the arch radius, angle of inclination, number of buckling half-waves, hanger cross-section factors, etc. However, the application of both critical forces is possible only when the stiffening girder is absolutely rigid. There are no solutions for the versions with the flexible chord. In general, the scope and the results of the research on the stability of network arch bridges are poor. Due to the large static uncertainty the engineering calculation methodology is quite primitive. It is known that the arch buckling resistance depends on the amount of hangers, the nature of the load and the arch bending stiffness (Schanack, 2009). It is stated that the effect of bending stiffness of the stiffening girder on the arch stability is low (Schana$\mathrm{ck}, 2009$ ). It has been established that the critical force of the network arch bridge arches is approximately 4 times the critical force of the arches with vertical hangers (Larssen \& Jakobsen, 2011). In one of the most recent articles (Backer, Outtier, \& Bogaert, 2014) a numerical experiment was performed to determine the in-plane arch buckling length factor at the elastic-plastic stage while modelling a real arch bridge by finite plane elements.

Meanwhile, the application area of Figure D.4 of Annex D, Eurocode 1993-2 is not defined. The ratio between the bending stiffness of the arch and the girder, the identification of buckling length factor values for the cases of more than 11 hangers, the static structure of the bridge and the shape of the arch are not known as yet. The application possibilities for the curves of buckling length factor for the purpose of establishing the buckling stability of the arch bridges with inclined hangers and arches of the network arch bridges which had long been known have not been defined as well. Dutch researchers have also highlighted the limited possibilities for the application of Figure D.4 (Romeijn \& Bouras, 2008). In order to extend to the application boundaries of the mentioned Eurocode Figure a numerical experiment was conducted for a model of arch bridges with pre-tensioned hangers and a rigid arch and stiffening girder connection.

The article presents a comparative analysis of the buckling length factor of the steel arch bridges with vertical hangers and network arch bridges with the use of numerical methods. The main assumptions are established which were used to constitute the dependence curves of the buckling length factors of Eurocode Annex D Figure D.4. The research presents the buckling length factor dependence on the number of hangers and grid shape.

\section{The comparative analysis of the buckling length factor of arch bridges with vertical hangers}

This chapter deals with the numerical and analytical experiments to determine the limits of the application of Figure D.4 of the Eurocode 1993-2 for steel arch bridges with vertical hangers. The buckling length factor values of the single arches with hinged or rigid supports are presented in the form of curves in Table D.4 of Annex D, depending on the height of the rise and the span length as well as on the shape of the arch. Likewise, Annex D, Figure D.4 presents the values of the buckling length factor of arches with a tension chord and vertical hangers connected to it, which, in addition to this, are dependent on the number of hangers. As the amount of hangers increases, the arch supporting effect grows. The value of the buckling length factor decreases respectively, and the critical buckling strength of the arch increases.

In order to determine the conditions and assumptions of the application of the Figure D.4 of the Eurocode 1993-2, stability analysis was carried out with the use of "SOFiSTiK" - the finite elements software. Three arch bridges with vertical hangers are modelled: in the first one the arch and the stiffening girder have separate foundations, in the second one the arch and the stiffening girder have a common foundation and one movable support, and in the third one both supports are rigid (Figure 1). The arch is connected flexibly to the stiffening girder. For each model of the arch the values of axial forces and buckling parameters are obtained. The critical buckling force given in Annex D of the Eurocode is analogous to the expression of Euler's critical force where the arch's calculated length is equal to the product of multiplying of the half length of the arch and the buckling length factor. The expression of the buckling length factor is obtained by converting the buckling critical force expression given in Annex $\mathrm{D}$ of the Eurocode 1993-2, where the critical force is equal to the product of multiplying of the arch's axial force and the buckling parameter calculated by numerical methods:

$$
\beta=\frac{\pi}{s} \sqrt{\frac{N_{E d} \psi}{E I_{y}}},
$$

where $\psi$ is the buckling parameter received from the FEM program analysis results, $N_{E d}$ is the axial compression force acting in the arch, $s$ is the half length the arch, $E I_{y}$ is the arch bending stiffness where the arch in-plane buckling takes place.

While interpreting the buckling length factor curve, when the arch is connected with the chord by a single hanger, it may be assumed that Figure D.4 is based on the first graph of Table D.4: a two-hinged parabolic arch. 

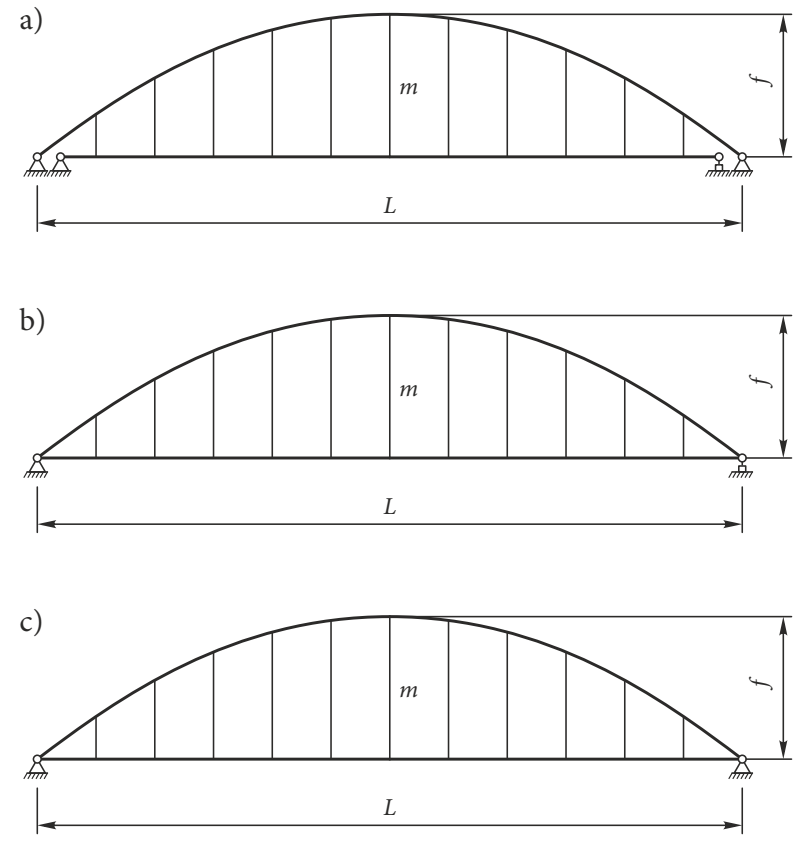

Figure 1. (a) a two-hinged single arch connected with the stiffening girder by hangers; (b) a tied arch bridge; (c) an arch bridge

Therefore, for the purpose of comparative analysis three different static schemes of two-hinged arch bridges were modelled: a single two-hinged arch connected by vertical hangers with a stiffening girder (Figure 1a), a tied arch bridge (Figure 1b), an arch bridge (Figure 1c). The number of vertical hangers $m$ is analogous to that of the Eurocode Figure D.4: $m=1 ; 2 ; 3 ; 5 ; 11$.

Since the bending stiffness ratio between the arch and the stiffening girder is not defined, marginal ratios are selected. The bending stiffness ratio of the first (Figure 1a) and third (Figure 1c) scheme arch and stiffening girder is equal to 2135 .

The ratio of the second scheme (Figure $1 b$ ) is respectively equal to 2135 , when the arch is rigid and the girder is slender; 1 , when the bending stiffness ratios of the arch and stiffening girder are equal; 0 , when the arch is slender and the stiffening girder is rigid.

Arch rise height and span length ratio $f / L=0.2$. The bridge load is uniformly distributed along the stiffening girder. Deck of the bridge is evaluated for calculation of the buckling length. Arch and girder section - IPE and HEB. For each arch rise height and span length ratio $f / L$ are selected different size of the cross section.

Table 1 presents the calculation results for each arch model: the values of the buckling length factor from Figure D.4 of the Eurocode and their respective critical forces, and the values of the $\beta$ factor obtained by means of the numerical experiment and their respective critical forces. The right column of the table presents the calculation errors.

The results of the comparative analysis presented in Table 1 and Figure 2 show that the buckling length factor $\beta$ curves given in Annex D, Figure D.4 of the Eurocode

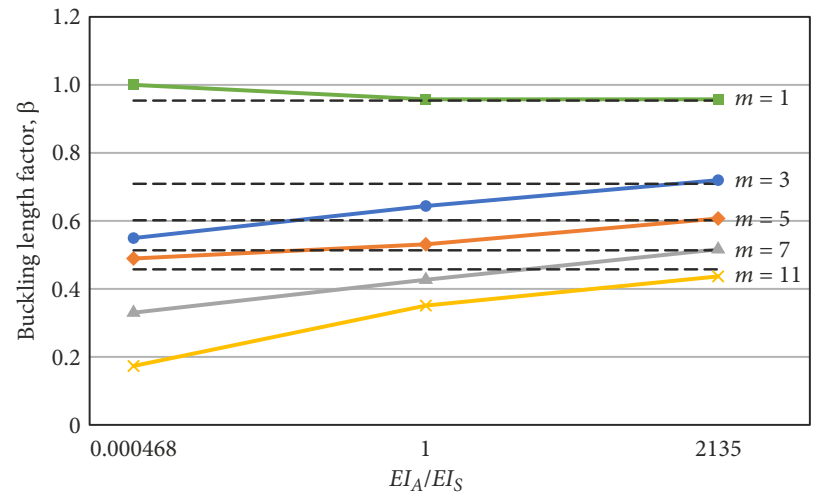

Figure 2. The comparative analysis of the numerical and analytical values of the buckling length factor

are valid in the case of the tied bridge and the bending stiffness of the stiffening girder is close to zero compared to the arch bending stiffness. The difference in numerical analysis results reaches up to $5.19 \%$.

When the arch is connected with a stiffening girder by a single hanger, the stability behaviour of the arch is close to the stability of the single arches: an insignificant hanger support effect is obtained, while most of the total load is taken over by the arch. The calculated buckling length factor values are close to the values presented in Figure D.4, regardless of the static scheme of the bridge (difference up to $0.65 \%$ ).

As the number of hangers $m$ increases, the difference between the theoretical and the numerically calculated buckling length factor values grows depending on the static scheme of the bridge. In case of 11 hangers on the arch bridge the difference is between $30 \%$ (bending stiffness ratio of the arch and stiffening girder equals 1 ) and $170 \%$ (bending stiffness ratio of the arch and stiffening girder equals 0.0005 ).

The increase in the bending stiffness of the stiffening girder reduces the part of the load attributed to the arch. Correspondingly, the buckling length factor of the arch decreases as well, while the critical force increases. The numerical experiment has established that the reserve of value of the buckling length factor given in Figure D.4 of the Eurocode is $30-152 \%$. In the Figures 3-6 are illustrated bending moments and axial forces in the arch and girder.

For the further calculations a tied arch bridge scheme is used with a bending stiffness ratio of the arch and stiffening girder equal to 2135

\section{The comparative analysis of the buckling length factor of the network arch bridges}

This chapter also deals with a numerical experiment carried out with the use of the finite elements software "SOFiSTiK" to determine the stability assessment possibilities of the network arch bridges with the use of the curves presented in Figure D.4 of the Eurocode 1993-2. The network arch bridges are characterized by a larger number of hangers compared to the traditional arch bridges. 
Table 1. The comparative table of the numerical and analytical values of the buckling length factor

\begin{tabular}{|c|c|c|c|c|c|c|}
\hline \multirow{2}{*}{ Scheme No. } & \multirow{2}{*}{$E I_{A} / E I_{S}$} & \multicolumn{2}{|c|}{ SOFiSTiK } & \multicolumn{2}{|c|}{ EC 3-2 } & \multirow{2}{*}{$\%$} \\
\hline & & $\operatorname{Ncr}(M N)$ & $\beta$ & $\operatorname{Ncr}(M N)$ & $\beta$ & \\
\hline $\mathrm{A}$ & 2135 & 3.53 & 0.962 & 3.57 & \multirow{5}{*}{0.956} & 0.65 \\
\hline \multirow{3}{*}{ B } & 2135 & 3.53 & 0.961 & 3.57 & & 0.52 \\
\hline & 1 & 3.54 & 0.961 & 3.57 & & 0.56 \\
\hline & 0.0005 & 0.00153 & 0.998 & 0.00167 & & 4.40 \\
\hline $\mathrm{C}$ & 2135 & 3.53 & 0.962 & 3.57 & & 0.63 \\
\hline A & 2135 & 3.81 & 0.925 & 6.46 & \multirow{5}{*}{0.711} & 30.10 \\
\hline \multirow{3}{*}{ B } & 2135 & 6.27 & 0.722 & 6.46 & & 1.47 \\
\hline & 1 & 7.88 & 0.644 & 6.46 & & 10.47 \\
\hline & 0.0005 & 0.00495 & 0.556 & 0.00302 & & 27.93 \\
\hline $\mathrm{C}$ & 2135 & 3.82 & 0.925 & 6.46 & & 30.02 \\
\hline A & 2135 & 3.93 & 0.911 & 9.07 & \multirow{5}{*}{0.6} & 51.85 \\
\hline \multirow{3}{*}{ B } & 2135 & 8.82 & 0.608 & 9.07 & & 1.39 \\
\hline & 1 & 11.48 & 0.533 & 9.07 & & 12.51 \\
\hline & 0.0005 & 0.00638 & 0.490 & 0.00425 & & 22.53 \\
\hline $\mathrm{C}$ & 2135 & 3.95 & 0.910 & 9.07 & & 51.59 \\
\hline A & 2135 & 4.02 & 0.901 & 12.5 & \multirow{5}{*}{0.511} & 76.34 \\
\hline \multirow{3}{*}{ B } & 2135 & 12.19 & 0.517 & 12.5 & & 1.25 \\
\hline & 1 & 17.84 & 0.428 & 12.5 & & 19.47 \\
\hline & 0.0005 & 0.014 & 0.330 & 0.00585 & & 54.71 \\
\hline $\mathrm{C}$ & 2135 & 4.04 & 0.899 & 12.5 & & 75.87 \\
\hline $\mathrm{A}$ & 2135 & 4.11 & 0.891 & 15.5 & \multirow{5}{*}{0.459} & 94.11 \\
\hline \multirow{3}{*}{ B } & 2135 & 17.15 & 0.436 & 15.5 & & 5.19 \\
\hline & 1 & 26.3 & 0.352 & 15.50 & & 30.26 \\
\hline & 0.0005 & 0.0512 & 0.173 & 0.00726 & & 165.51 \\
\hline $\mathrm{C}$ & 2135 & 4.14 & 0.888 & 15.5 & & 93.97 \\
\hline
\end{tabular}
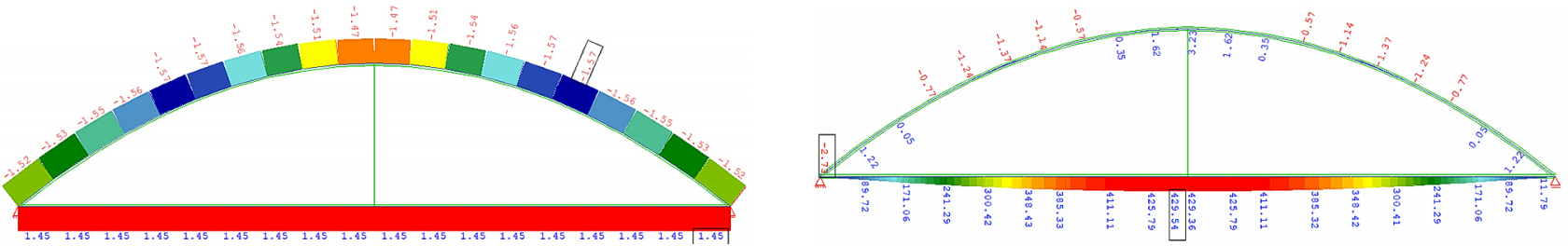

Figure 3. Axial forces and bending moments of a tied arch bridge
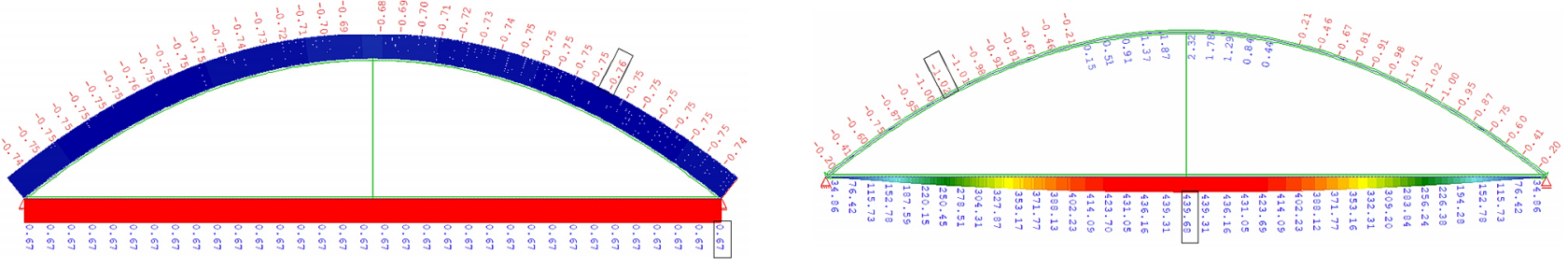

Figure 4. Axial forces and bending moments of an arch bridge
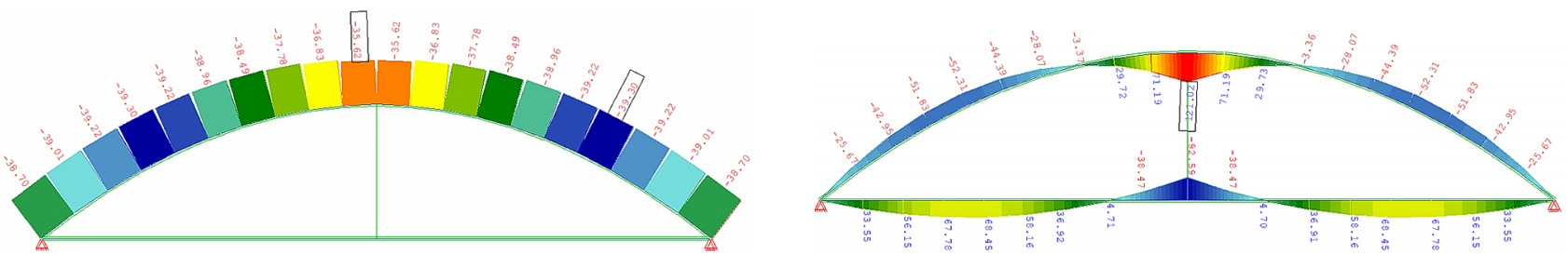

Figure 5. Axial forces and bending moments of two-hinged single arch connected with the stiffening girder by hangers 
Moreover, the bridges of this type are much more rigid in plane. Only the application for arches with vertical hangers is graphically defined in Figure D.4 of the Eurocode. Therefore, while designing steel arch bridges with crisscross or diagonal hanger arrangement according to the buckling length factor values $\beta$ presented in the Eurocode, the reserve can reach several times that amount.

For the purpose of comparative analysis, five tied network arch bridges are modelled (Figure 3). The original angles between intersecting hangers are selected which are $\alpha=30^{\circ}, 40^{\circ}, 45^{\circ}$ and the respective number of hangers: $m=14,20,28$ and 40 . The geometry of the grid of the network arch bridges is circular (Backer et al., 2014; Brunn \& Schanack, 2003): the hangers intersecting with the arch at constant angle divide it into equal parts. Thus, the vertical loads are moved as far as possible in the radial direction and a local curvature of the arch radius occurs, while all of this results in small bending moments in the arch and buckling resistance.

Similarly to the first part of the analysis for each model of the arch the values of axial forces and buckling parameters are obtained in a numerical way. The product of these two is equal to the critical force of the arch. The value of the buckling length factor is calculated according to formula no. 1 discussed in the first part of the article. The buckling length factor values $\beta$ calculated numerically are compared with the buckling length factor value selected in Figure D.4 of the Eurocode 1993-2. It is assumed that $\beta_{\mathrm{EC}}=0.459$, while the number of hangers equals 11 . Arch rise height and span length ratio $f / L=0.2$. The bridge load is uniformly distributed along the stiffening girder. Buckling length factor difference is expressed as a percentage.

The calculation results are presented in Table 2.

The first part of Table 2 presents the constant buckling length factor value obtained from Figure D.4 of the Eurocode 1993-2 while the number of hangers equals 11 . The second part of the table shows the buckling length factor values obtained and calculated numerically. The third part of the table presents the difference in percentage form.

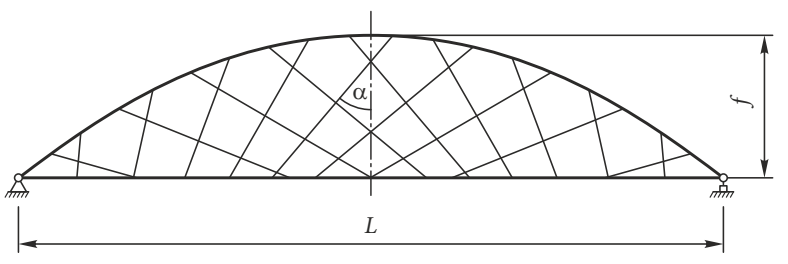

Figure 6. Network arch bridge

Table 2. The comparative table of the numerical and analytical values of the buckling length factor

\begin{tabular}{|c|c|c|c|c|}
\hline \multicolumn{7}{|c|}{ EC3-2 } \\
\hline 0.459 & 0.459 & 0.459 & 0.459 & 0.459 \\
\hline \multicolumn{5}{|c|}{ Network arch bridge, FE } \\
\hline$m=14, \alpha=45^{\circ}$ & $m=28, \alpha=45^{\circ}$ & $m=28, \alpha=30^{\circ}$ & $m=20, \alpha=40^{\circ}$ & $m=40, \alpha=40^{\circ}$ \\
\hline 0.383 & 0.338 & 0.285 & 0.348 & 0.297 \\
\hline \multicolumn{5}{|c|}{ Difference, $\%$} \\
\hline
\end{tabular}

The provided results show that as the number of hangers increases, the value of the buckling length factor decreases and the critical force increases accordingly. The difference is up to 1.6 times or $61.05 \%$. The value of the $\beta$ factor of the arches with fourteen vertical hangers is approximately $19.84 \%$ less than the standard one on Figure D.4 of the Eurocode 1993-23. Therefore, the application area of the Eurocode is very small in the design of network arch bridges. The presented results show that Figure D.4 must be supplemented not only by the number of hangers but also by angle $\alpha$ which characterizes the intersection of the hangers.

\section{Conclusions}

The article provides a comparative analysis of the buckling length factor. The values presented as curves in Eurocode Annex D Figure D.4 and calculated by means of finite elements software "SOFiSTiK" were compared. The aim of the first part of the analysis is to determine the assumptions for arch bridge modelling under which the dependence of the ratio between the buckling factor and the height of the rise as well as the span length is valid. The numerical experiment result error is up to $5.20 \%$ in case of a tied bridge and the ratio of the bending stiffness of the stiffening girder relatively equal to zero. The increase of the bending stiffness of the stiffening girder causes the buckling length factor values to be $30-152 \%$ greater than the normative $\beta_{\mathrm{EC}}$ value.

In the second part of the comparative analysis the buckling length factor value was established by a numerical experiment with the increase in the number of hangers and changing the hanger network form. It was established that as the number of hangers increases, the $\beta$ factor decreases (from $14.20 \%$ up to $61.05 \%$ compared to the normative $\beta_{\mathrm{EC}, \mathrm{m}}=11$ ), and the critical force increases accordingly.

In conclusion, the application area of Figure D.4 of Annex D, Eurocode 1993-2 is limited. In order to increase the economic efficiency and design accuracy, it is recommended that the dependence of the buckling length factor values should be supplemented by a bending stiffness ratio between the arch and the stiffening girder, a number of hangers greater than 11 and a new form of hanger grid. 


\section{References}

Backer, H. D., Outtier, A., De Pauw, B., \& Van Bogaert, Ph. (2010). Long-term monitoring of temperatures in steel box girders. Paper presented at the 34th International Symposium on Bridge and Structural Engineering (IABSE - 2010) (pp. 1-8). Venice, Italy.

Backer, H. D., Outtier, A., \& Bogaert, Ph. V. (2014). Buckling design of steel tied-arch bridges. Journal of Constructional Steel Research, 79, 159-167. https://doi.org/10.1016/j.jcsr.2014.09.004

Brunn, B., \& Schanack, F. (2003, August). Calculation of a double track railway network arch bridge applying the European standards. Technische Universität Dresden, Grimstad.

Brunn, B., Schanack, F., \& Steimann, U. (2004). Network arches for railway bridges. In P. Roca \& C. Molins (Eds.), Advances in assessment, structural design and construction. Paper presented at the Arch bridges IV, International Center for Numerical Methods in Engineering (pp. 1-9). Barcelona.

Galambos, T. V. (Ed.). (1988). Guide to stability design criteria for metal structures (4th ed., pp. 669-703). New York, NY, USA: John Wiley \& Sons.

Graße, W., Teich, S., Tveit, P., \& Wendelin, S. (2004). Network arches for road bridges. In Advances in assessment, structural design and construction. Paper presented at the Arch bridges IV, International Center for Numerical Methods in Engineering (pp. 1-10). Barcelona.

Guo, Z., Wang, Y., Lu, N., Zhang, H., \& Zhu, F. (2016). Behaviour of a two-pinned steel arch at elevated temperatures. ThinWalled Structures, 107, 248-256.

https://doi.org/10.1016/j.tws.2016.06.015

Heidarpour, A., Bradford, M. A., \& Othman, K. A. M. (2011). Thermoelastic flexural-torsional buckling of steel arches. Journal of Constructional Steel Research, 67, 1806-1820. https://doi.org/10.1016/j.jcsr.2011.05.005

Larssen, R. M., \& Jakobsen, S. E. (2011). Brandangersundet bridge - a slender and light network arch, taller, longer, ligher. Paper presented at the IABSE-IASS-2011 London Symposium Report, 20-23 September, London, United Kingdom.

Lebet, J.-P., \& Hirt, M. (2013). Steel bridges: conceptual and structural design of steel and steel-concrete composite bridges (pp. 461-488). New York, NY, USA: Taylor and Francis Group.

Lietuvos Standartizacijos departamentas. (2007). Eurokodas 3. Plieniniu konstrukciju projektavimas. 2 dalis. Plieniniai tiltai (LST EN 1993-2:2007/NA:2010). Retrieved from https://lsd. lt/index.php?1323599487

Pi, Y.-L., \& Trahair, N. S. (1999). In-plane buckling and design of steel arches. Journal of Structural Engineering, ASCE, 125(11), 1291-1298. https://doi.org/10.1061/(ASCE)0733-9445(1999)125:11(1291)

Pi, Y.-L., \& Bradford, M. A. (2004). In-plane strength and design of fixed steel I-section arches. Engineering Structures, 26(3), 291-301. https://doi.org/10.1016/j.engstruct.2003.09.011

Pi, Y.-L., \& Bradford, M. A. (2006). Elastic flexural-torsional buckling of circular arches under uniform compression and effects of load height. Journal of Mechanics of Materials and Structures, 1(7), 1235-1255.

https://doi.org/10.2140/jomms.2006.1.1235

Pi, Y.-L., \& Bradford, M. A. (2014). Effects of nonlinearity and temperature field on in-plane behavior and buckling of crown-pinned steel arches. Engineering Structures, 74, 1-12. https://doi.org/10.1016/j.engstruct.2014.05.006
Pi, Y.-L., \& Bradford, M. A., \& Tin-Loi, F. (2008). In-plane strength of steel arches. Advanced Steel Construction, 4(4), 306-322. https://doi.org/10.18057/IJASC.2008.4.4.3

Romeijn, A., \& Bouras, C. (2008). Investigation of the arch inplane buckling behaviour in arch bridges. Journal of Constructional Steel Research, 64, 1349-1356. https://doi.org/10.1016/j.jcsr.2008.01.035

Schanack, F. (2009). Berechnung der Knicklast in Bogenebene von Netzwerkbögen. Stahlbau, 86(5), 249-255. https://doi.org/10.1002/bate.200910022

Teich, S. (2011). Entwicklung allgemeiner Entwurfsgrundsätze für Hängernetze von Netzwerkbogenbrücken. Stahlbau, 80(2), 100-111. https://doi.org/10.1002/stab.201001395

Tveit, P. (2005, August). The network arch, Bits of Manuscript after lectures in 34 countries. Retrieved from https://home.uia. no/pert

Zhao, S.-Y., Guo, Y.-L., \& Dou, C. (2013). Geometric imperfection effects on out-of-plane inelastic buckling loads of lateral braced arches. In Proceedings of the 10th Pacific Structural Steel Conference, 8-11 October, Singapore (pp. 181-186). Singapore: Research Publishing Services. https://doi.org/10.3850/978-981-07-7137-9_072

Ziemian, R. D. (2010). Guide to stability design criteria for metal structures (6th ed., pp. 762-806). New York, NY, USA: John Wiley \& Sons. https://doi.org/10.1002/9780470549087.ch17 